\title{
Tracking down the Cause of Necrotizing Fasciitis in a Patient with Negative Cultures
}

Vierhout BP ${ }^{1 *}$, van Zanten $\mathrm{E}^{2}$, Wisselink $\mathrm{G}^{2}$, Kooistra-Smid $M^{2,3}$ and Ott $A^{2}$

${ }^{1}$ Department of Surgery, Wilhelmina Ziekenhuis, Assen, The Netherlands

${ }^{2}$ Department of Medical Microbiology, Certe, Groningen, The Netherlands

${ }^{3}$ University of Groningen, University Medical Center Groningen, Department of Medical Microbiology, Groningen, The Netherlands

*Correspondling author: Vierhout Bas P, Department of Surgery, Wilhelmina Hospital, Europaweg-Zuid 1, 9401 RK Assen, Netherlands

Received: March 16, 2018; Accepted: April 19, 2018; Published: May 07, 2018

\begin{abstract}
Necrotizing Fasciitis (NF) is a severe disease of sudden onset that spreads rapidly [1]. Risk factors include poor immune function and a breaks through the skin-barrier; for instance a wound. Symptoms comprise red skin, severe pain and fever. Surprisingly, also healthy persons suffer from NF, without a visible entrance through the skin and mainly in the perineal region or the limbs.

The disease is feared because of its high mortality and subsequent morbidity. The infection spreads rapidly over the fascia of the muscles and open surgical drainage is the only treatment option: Infected tissue must be removed without delay, in combination with intravenous antibiotics.

Most often, the causative agent is a Streptococcus from Lancefield group A (S. pyogenes). When S. pyogenes is involved antibiotic treatment with a high dose of penicillin suffices. But combinations of antibiotics with a broader spectrum are required in infections in the perineal area, because these may be polymicrobial.
\end{abstract}

\section{Case Presentation}

A 68-year-old female patient complained of severe pain and localized redness since a few hours, spreading over the lower abdomen. Four days before, she had some localized pain on the right side of the abdomen, which gradually shifted to the left. Mobilizing aggravated the pain and made her nauseous, and as a result, she ate and drank less. She had no abdominal surgery or medical history in the past. Only bad teeth had been removed 6 years earlier, to replace them by prosthesis.

At the emergency room she had a fever of $39.2^{\circ} \mathrm{C}$, with a pulse of 107 per minute and a tension of $111 / 63 \mathrm{mmHg}$. The abdominal tenderness and redness was moderately delimited and there was no swelling (Figure 1). Some bowel sounds were heard and the redness felt firmer than the surrounding tissue.

Laboratory tests showed a leukocytosis of $44,000^{\star} 106$ per liter, with a left upper shift. A hyponatremia was accompanied by elevated urea and creatinine level of $23.3 \mathrm{mmol} / \mathrm{l}$ and $272 \mu \mathrm{mol} / \mathrm{l}$, respectively. C-reactive protein was $639 \mathrm{mg} / \mathrm{l}$. An emergency CT-scan did not show intra-abdominal disorder: no abnormal air or fluid collection in the abdominal cavity and normal intraabdominal organs. But the subcutaneous fat of the anterior abdominal wall showed signs of inflammation without gas.

The patient was started on piperacillin with tazobactam in combination with clindamycin and surgical exploration was performed on suspicion of NF. During the operation the fascia seemed intact, but the subcutaneous tissue, adjacent to the fascia had a discolored, greyish, avital aspect. Biopsies for cultures and histology of the tissue were taken and the wound was left open.

\section{Microbiology}

Blood cultures taken on admission and culture of the tissue

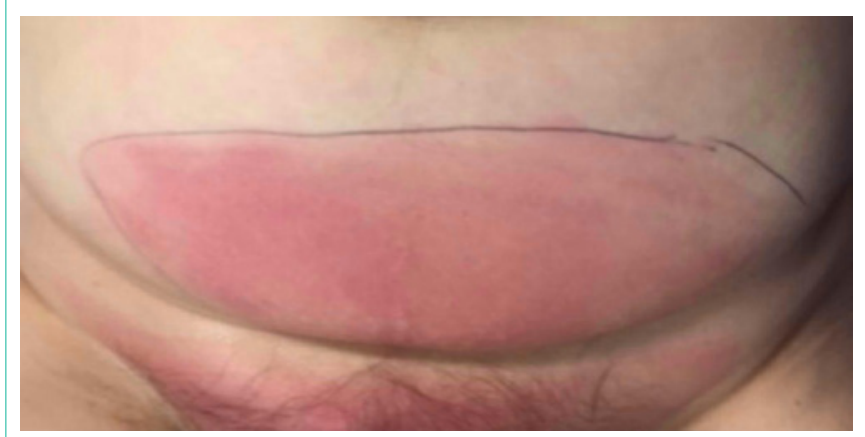

Figure 1: The patient before surgery. The line around the redness was drawn in the emergency department in order to identify an increase.

taken during surgery unfortunately remained negative. No bacteria were seen in the Gram stain of the tissue. Because of these negative findings and uncertainty about the best choice of antibiotics to continue the treatment we additionally examined the tissue with 16S-23S rDNA Next Generation Sequencing [2]. This method is based on a PCR amplification of the 16S-23S rRNA region followed by amplicon sequencing on the MiSeq (Illumina, Inc., San Diego, $\mathrm{CA}$ ). The resulting reads are denovo assembled into contigs. Species identification is based on an alignment of the contig sequences with the sequences deposited in the reference databases. This resulted in identification of Streptococcus pyogenes only, with a relative abundance (RA) of $99.7 \%$. The RA indicates the relative percentage of reads that represents the same species in a sample [3].

\section{Discussion}

The best remedy for NF is early recognition, followed by surgery and antibiotic treatment focused upon the causative agent(s). Unfortunately, in some cases, these agents cannot be identified, as was the case in this patient. Most likely this was due to the high dose
Austin J Obstet Gynecol - Volume 5 Issue 6 - 2018

Submit your Manuscript | www.austinpublishinggroup.com

Vierhout et al. (C) All rights are reserved
Citation: Vierhout BP, van Zanten E, Wisselink G, Kooistra-Smid M and Ott A. Tracking down the Cause of Necrotizing Fasciitis in a Patient with Negative Cultures. Austin J Obstet Gynecol. 2018; 5(6): 1115. 
of intravenous antibiotic that was already given at the emergency department. The infection was in an early stage and therefore tissue circulation was still intact. Streptococcus pyogenes is usually highly sensitive to the penicillin class antibiotics.

Knowing the causative bacteria enabled us to finish the treatment with oral amoxicillin after the patient recovered. 16S-23S rDNA NGS could exclude the alternative diagnosis in this patient of the polybacterial Fournier NF, which requires a broader spectrum of antibiotics. 316S-23S rDNA NGS can therefore contribute to rational antibiotic use.

\section{References}

1. Stevens DL, Bryant AE. Necrotizing Soft-Tissue Infections. N Engl J Med. 2017; 377: 2253-2265.

2. Sabat AJ, van Zanten E, Akkerboom V, Wisselink G, van Slochteren K, de Boer RF, Hendrix et al. Targeted next-generation sequencing of the 16S-23S rRNA region for culture-independent bacterial identification - increased discrimination of closely related species. Sci Rep. 2017; 7: 3434.

3. Mallikarjuna MN, Vijayakumar A, Patil VS, Shivswamy BS. Fournier's Gangrene: Current Practices. ISRN Surg. 2012: 942437.
Austin J Obstet Gynecol - Volume 5 Issue 6 - 2018

Submit your Manuscript | www.austinpublishinggroup.com

Vierhout et al. (C) All rights are reserved
Citation: Vierhout BP, van Zanten E, Wisselink G, Kooistra-Smid M and Ott A. Tracking down the Cause of Necrotizing Fasciitis in a Patient with Negative Cultures. Austin J Obstet Gynecol. 2018; 5(6): 1115. 